\title{
Suprascapular foramen: a rare variation caused by ossified suprascapular ligaments
}

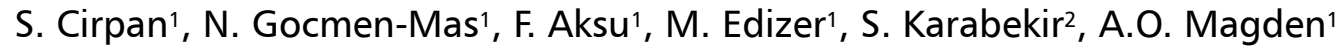 \\ ${ }^{1}$ Department of Anatomy, Faculty of Medicine, Dokuz Eylül University, Izmir, Turkey \\ 2Department of Neurosurgery, Faculty of Medicine, Dokuz Eylul University, Izmir, Turkey
}

[Received: 4 January 2015; Accepted: 29 April 2015]

\begin{abstract}
Background: The aim of this study was to investigate the incidence of the suprascapular foramen in West Anatolian population.

Materials and methods: Eighty-one dried human scapulae of West Anatolian people of unknown ages and gender belonging to the Anatomy Department Laboratory of Dokuz Eylul University Medical School were examined macroscopically. The vertical and transverse diameters of the suprascapular foramen and central thickness of the ossified ligaments were measured with calliper in millimetres and digital calliper, respectively.

Results: We observed the suprascapular foramen due to ossification of the suprascapular ligament only in 2 of $81(2.47 \%)$ scapulae. The vertical and transverse diameters of the suprascapular foramen and central thickness of the ossified ligaments (No. 1 and No. 2) were measured as $8.0 \mathrm{~mm}$ vs. $4.0 \mathrm{~mm}, 3.6 \mathrm{~mm}$ vs. $2.0 \mathrm{~mm}$ and $4.0 \mathrm{~mm}$ vs. $1.4 \mathrm{~mm}$, respectively.

Conclusions: The suprascapular foramen caused by ossified suprascapular ligament is rarely observed variation in West Anatolian population. (Folia Morphol 2016; 75, 1: 21-26)
\end{abstract}

Key words: suprascapular foramen, suprascapular notch, suprascapular ligament

\section{INTRODUCTION}

The suprascapular notch (SSN) is located on the lateral part of the superior margin of the scapula and medial to the coracoid process. The superior transverse scapular ligament (STSL) transforms this notch to a foramen [37]. The suprascapular nerve (SN) and vein pass through the foramen below this ligament [28]. Fibers from the roots of $\mathrm{C} 5$ and $\mathrm{C} 6$ and occasionally C4 combine to form the SN [50]. The size and shape of the SSN can cause SN entrapment [11]. The entrapment of the SN may be due to the congenital abnormalities of the upper margin of the scapula, fractures of the scapula, ganglion cysts or tumours, stretching of the nerve, anomalously formed suprascapular ligaments and an ossified suprascapular ligament $[3,13]$.

The scapular notch is changed into a bony foramen by ossification of the suprascapular ligament and this may result in $\mathrm{SN}$ entrapment $[34,36,46]$. The SN is usually compressed mainly at the level of SSN or the base of scapular spine [27]. The variations of SSN and STSL are predisposing factors to SN entrapment [35].

Kopell and Thompson [24] are the first investigators that described this disorder. The SN entrapment causes severe shoulder pain and disability. The shoulder pain is increased by the adduction of the extended arm due to streching of the nerve [15]. The radiation of pain through the arm, restriction of the

Address for correspondence: S. Cirpan, MD, Dokuz Eylül University, Faculty of Medicine, Department of Anatomy, 35340, Inciralti, Izmir, Turkey, tel: +90 53368421 26, fax: +9023241297 98, e-mail: cirpansibel@hotmail.com 
shoulder movements such as abduction and external rotation, atrophy of the supraspinatus muscle may be observed [9].

The SN entrapment can lead to atrophy in the supraspinatus and infraspinatus muscles and fracture of collum scapula [15]. The sporting activities such as gymnastics, tennis, weightlifting, boxing and baseball pitching can compress the SN [36]. It is hypothesized that repetitive overhead motion or trauma leads to ossification of the ligament [50]. The athletes repeating forceful shoulder movements [21] or carrying heavy objects on a regular basis [20] are the population at risk for SN entrapment. The frequency of SN neuropathy was $33 \%$ amoung high-performance volleyball players [16].

The anatomical variations such as the aberrant course of the suprascapular artery (SSA) through the SSN [49] or the presence of a hypertrophied subscapularis muscle [5] are evaluated as a risk factor for SN entrapment [54]. SSN with an anomalous STSL is most observed predisposing factor for compression at the SSN, which have been demonstrated both in anatomy dissection and clinical settings $[6,9,47]$. According to the previous investigations, STSL was partially or completely ossified, and the incidence of partial and complete ossification of STSL were reported as $18 \%$ and $5 \%$, respectively [47]. Furthermore, the incidence of partial ossification of STSL was also noted as $3.7-4 \%$ by Hrdlicka et al. [17] and Rengachary et al. [42]. Moriggl declared that the calcified STSL was a sign of entrapment [29]. The present study deals to investigate the incidence of suprascapular foramen in West Anatolian population.

\section{MATERIALS AND METHODS}

Eighty-one dried human scapulae of West Anatolian people of unknown ages and gender belonging to the Anatomy Department Laboratory of Dokuz Eylul University Medical School were examined. Official permission for this investigation was obtained from Dokuz Eylul University Medical School. None of the specimens showed the signs of prior surgery or trauma. The analysis and determination of the suprascapular foramen were made by macroscopic observation of the scapulae. The vertical and transverse diameters of the foramens and central thickness of the ossified ligaments were measured with calliper in millimetres and digital calliper (Mitutoyo, Japan), respectively.

\section{RESULTS}

In the present study, 57 left and 24 right scapulae were evaluated. We observed foramen scapulae due to ossified suprascapular ligaments only in $2(2.47 \%)$ of 81 scapulae (Figs. 1, 2). The vertical and transverse diameters of the suprascapular foramina (No. 1 and No. 2) were measured as $8.0 \mathrm{~mm}$ vs. $4.0 \mathrm{~mm}$ and $3.6 \mathrm{~mm}$ vs. $2.0 \mathrm{~mm}$, respectively. The central thickness of this two ossified suprascapular ligaments (No. 1 and No. 2) were $4.0 \mathrm{~mm}$ vs. $1.4 \mathrm{~mm}$, respectively (Table 1 ).

\section{DISCUSSION}

The ossification of the cartilaginous scapula begins in 8 or more centres in intrauterine life, and joining of the various epiphyses of scapula occurs by about 20 years of age [19].

Many investigators found that the incidence of complete ossification of STSL varied from $3.7 \%$ to $13.6 \%[6,11,12,17,33,41-43,47,49,51]$. Vallois reported $6.1 \%$ bony foramen in Italian scapulae [53]. Polguj et al. [37] found that the rate of bony foramen was $7 \%$ in their study. Olivier et al. [33] and Vallois [52] found the incidence of the scapular foramen in France as $5 \%$ and $6.5 \%$, respectively. Natsis et al. [32] reported the incidence as $7.3 \%$ of 423 scapulae in Germany. In some studies in United States, the incidence of complete ossification of STSL were found $3.7 \%, 4 \%$ and $5 \%$, respectively $[11,12,43,47,49]$. There was also only one complete ossification of STSL in Indian scapulae in one study [22].

Toneva et al. [48] reported that the incidence of the suprascapular foramen in the osteological material collected from medieval necropoles in the territory of North-Eastern Bulgaria $\left(9^{\text {th }}-11^{\text {th }}\right.$ century AD) was $2.9 \%$.

Bayramoglu et al. [6] investigated calcified STSL in cadavers and found the incidence of suprascapular foramen as $12.5 \%$ (4 of 32 scapulae) in Turkey. In West Anatolian population, we found this incidence as $2.47 \%$ (2 of 81 scapulae) in the present study. This difference of incidence of scapular foramina in Turkish population may be due to the diverse geographical regions of Turkey in which these investigations were done.

The occurrence of the foramina could be genetically affected [37]. The incidence of complete ossification of the STSL is observed as $0.2 \%$ in the Alaskan Eskimo [17]. The variation in these incidences may be due to both genetic and geographical differences 


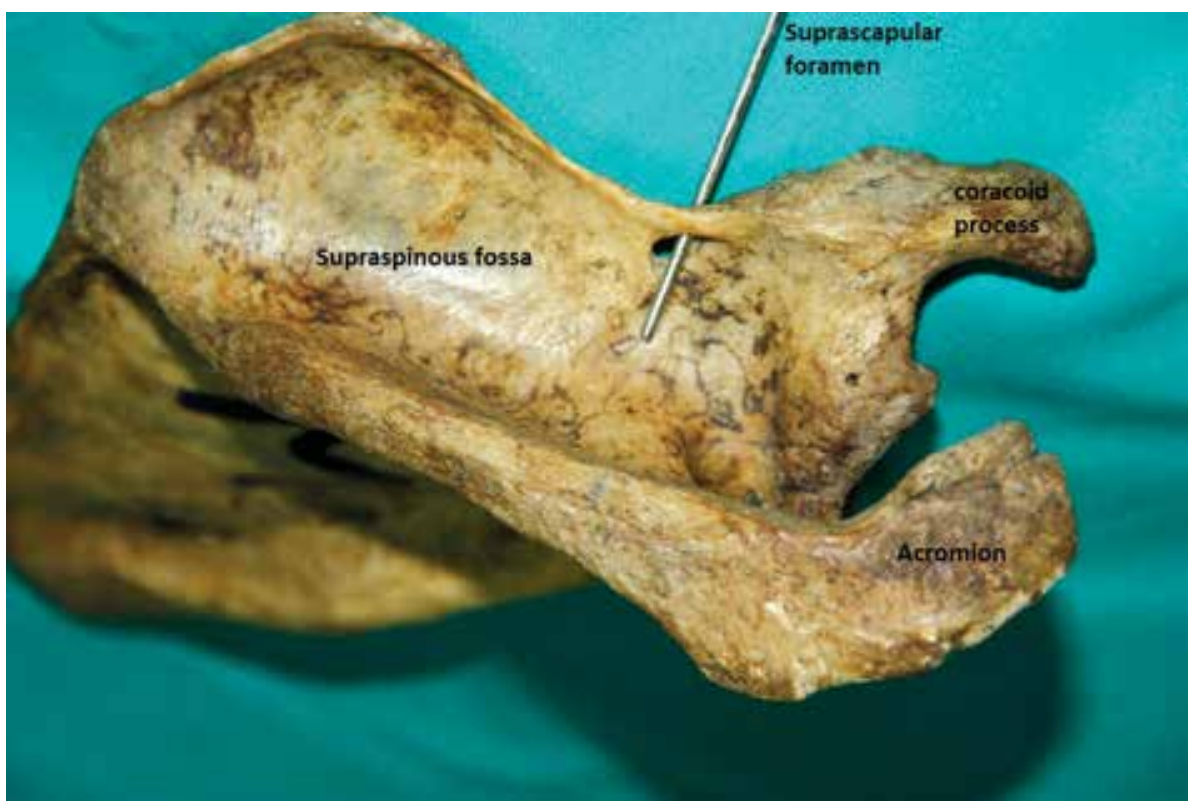

Figure 1. The suprascapular foramen on the right side (No. 1).

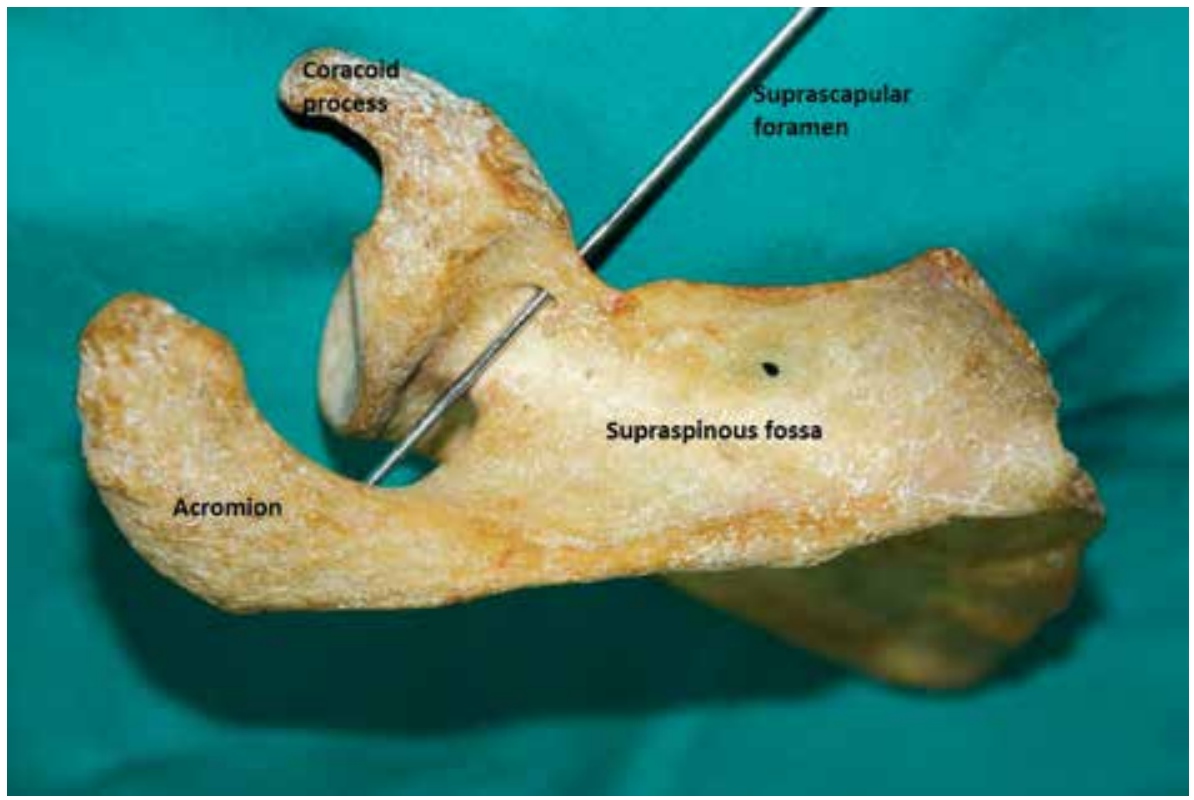

Figure 2. The suprascapular foramen on the left side (No. 2).

Table 1. Measurements of the foramen scapulae

\begin{tabular}{lccc}
\hline Specimen number & Vertical length foramen scapula & Transverse length foramen scapula & Central thickness of ossified ligament \\
\hline 1 (right scapula) & $8.0 \mathrm{~mm}$ & $3.6 \mathrm{~mm}$ & $4.0 \mathrm{~mm}$ \\
2 (left scapula) & $4.0 \mathrm{~mm}$ & $2.0 \mathrm{~mm}$ & $1.4 \mathrm{~mm}$ \\
\hline
\end{tabular}

existed in ethnic groups. Cohen et al. [9] described that a familial case of calcified STSL; which caused entrapment neuropathy of the $\mathrm{SN}$ resulting with pain, weakness and atrophy of the supraspinatus muscle; was affecting a 58-year-old man and his son, which suggested genetic inheritance for the ossification [9]. 
These differences observed in incidence may also be related to the variation in classification methods of SSNs and genetic inheritance [54]. Ticker et al. [47] classified the SSNs into 2 types and evaluated the degree of ossification of the STSL separately.

There are only 2 case reports which describe double suprascapular foramen in the literature $[18,54]$. In 1 study, a unique anatomical variation of the SSN which was converted into a double foramen (inferior and superior) by 2 bony bridges was observed [38]. In the present study we didn't find any double foramen.

The factors that may cause formation of SN entrapment are as follows: shape of the SSN [14, 21], shape of the STSL $[19,20]$, presence of the hypertrophied suprascapular muscle [7], an entirely ossified STSL $[8,13]$ or presence of a spinoglenoidal ligament [17]. In aetiology of the $\mathrm{SN}$ entrapment, less attention has been paid to the topography of the complete suprascapular triad: the nerve, artery and vein [39]. The SSA which supplies the supraspinatus muscle enters the supraspinous fossa on the dorsal aspect of the scapula superior to the STSL [26]. Naidoo et al. [31] investigated course of the SSA and found that $20 \%$ of the SSAs were located inferior to the STSL. When the route of the SSA passes under the STSL, it may cause SN entrapment [6, 44, 49]. Polguj et al. [39] found that specimens including type III suprascapular triad (the suprascapular vessels and nerve lie beneath the STSL) had smallest mean area of the suprascapular opening, when compared with the others.

Yücesoy et al. [55] observed that the suprascapular artery-vein complex always passed below STSL in a total of 43 from 50 (86\%) Turkish volunteers evaluated by colour Doppler ultrasound. This unusual location of the SSA causes SN entrapment due to compression of the SN $[1,8]$; however, the position of the $S N$ is probably the most important factor in formation of the SN entrapment $[23,44]$.

The close relation between the $\mathrm{SN}$ and vessels around the STSL is important to surgical dissection of this region. While surgeons that encounter the bleeding from these vessels during the resection of STSL are controlling haemorrhage, they should be aware of not causing damage to the SN [40].

Moriggl et al. [30] showed that the progression of endochondral ossification caused the bony spur at the superior edge of the SSN. Long-term ossification around the notch, which was caused by aging and mechanical loading, might have resulted in shortening of the STSL [45].
Avery et al. [2] discovered that the anterior coracoscapular ligament (ACSL) might have been supposed as a new possible mechanism for the formation of this anatomical variation. Polguj et al. [38] observed the presence of the ACSL as $60 \%$ of 54 dissected shoulders, and they found that the SN always has been passing under the ACSL; therefore, it has been in close contact to the bony floor of the SSN [38]. Bayramoglu et al. [6] stated ACSL as an additional aetiological factor of the $\mathrm{SN}$ entrapment, and they supposed that SSN was suitable only for crossing of the $\mathrm{SN}$; the notch became narrow for $\mathrm{SN}$ whether the SSA accompanied this nerve through the notch [6].

Wang et al. [54] found that the incisura scapulae had rough surfaces where the $\mathrm{SN}$ was vulnerable to frictional insults during back and forward movements of the shoulder. The thickness of SSN is always ignored but it actually varies. They found that thickness of SSN was ranging from 0.55 to $3.00 \mathrm{~mm}$ at $1 \mathrm{~mm}$ below the lowest point, and the thinner border was very sharp which may be the reason of the injury to the nerve as a result of repeating shoulder movements. The long bony canal and narrow SSN area increase the SN entrapment. The distances between the SSN and bony landmarks are important for preventing the neurovascular injury during surgical procedures [54].

There was no correlation between the notch type and the injury frequency although the differences of morphology were found in the notch $[11,46]$. The incidence of the $\mathrm{SN}$ entrapment has been found higher in Brazilians, and the incidence of foraminae was found higher on right sides of male cadavers than left side $(p<0.05)$ [46]. Tubbs et al. [50] concluded that higher rate of suprascapular foramina on right scapulae may be related to the right-hand dominance in general population. We found that 2 (1 right and 1 left scapula) of 81 scapulae had foramina.

Early diagnosis of the $\mathrm{SN}$ entrapment causing muscular atrophy is difficult before the occurrence of complaints such as deeply and poorly localised pain [10]. The treatment of the $\mathrm{SN}$ compression starts with physical therapy for strengthening the rotator cuff muscles [50]. The nerve blockage by a local anesthetic can relief the pain only for a short time and simultaneously provide diagnosis. The surgical treatment is used in case of constant pain and pathological changes in electromyography patterns [15]. Delayed conduction along the SN may be demonstrated by electromyographic tests [9]. It can be treated by surgical removal of the ossified transverse scapular ligament [15]. 
Gosk et al. [13] claimed that surgical outcomes depended on the length of time between onset of symptom and surgery itself, and pathology underlying the nerve compression. The surgical treatment of SN entrapment with arthroscopic decompression needs detailed anatomical information of the suprascapular region $[4,7,14,25]$.

\section{CONCLUSIONS}

The ossified suprascapular ligament narrows the suprascapular foramen [39]; therefore, it causes compression of $\mathrm{SN}$ and complaints of SN entrapment. It is essential to define precisely the anatomical variations of scapular notch, scapular ligament, SN and vessels for surgeons performing SN decompression surgery, especially with arthroscopic techniques. We assume that the present study may guide the medical doctors and the surgeons during diagnostic and surgical procedures related with SSN.

\section{REFERENCES}

1. Adibatti M, Prasanna LC (2010) Variation in origin of suprascapular artery. Int J Anat Variations, 3: 178-179.

2. Avery BW, Pilon FM, Barclay JK (2002) Anterior coracoscapular ligament and suprascapular nerve entrapment. Clin Anat, 15: 383-386.

3. Avon M, Weiss S, Fisher B, Dekel S (1988) Bilateral suprascapular nerve entrapment syndrome due to an anomalous transverse scapular ligament. Clin Orthop Relat Res, 234: 31-33.

4. Barwood SA, Burkhart SS, Lo IK (2007) Arthroscopic suprascapular nerve release at the suprascapular notch in a cadaveric model: an anatomic approach. Arthroscopy, 23: 221-225.

5. Bayramoglu A, Demiryurek D, Erbil M, Aktekin M, Tetik O, Doral MN (2002) Hypertrophy of the subscapularis muscle might be anetiologic factor for suprascapular nerve entrapment at thesuprascapular notch. Neuroanatomy, 1: 5-6.

6. Bayramoglu A, Demiryurek D, Tuccar E, Erbil M, Aldur MM, Tetik O, Doral MN (2003) Variations in anatomy at the suprascapularnotch possibly causing suprascapular nerve entrapment: an anatomical study. Knee Surg Sport Trauma Arthrosc, 11: 393-398.

7. Bhatia DN, de Beer JF, van Rooyen KS, du Toit DF (2006) Arthroscopic suprascapular nerve decompression at the suprascapularnotch. Arthroscopy, 22: 1009-1013.

8. Clein $\amalg(1975)$ Suprascapular entrapment neuropathy. J Neurosurg, 43: 337-342.

9. Cohen SB, Dines DM, Moorman CT (1997) Familial calcification of the superior transverse scapular ligament causing neuropathy. Clin Orthop Relat Res, 334: 131-135.

10. Das S, Suri R, Kapur V (2007) Ossification of superior transverse scapular ligament and its clinical implications. Sultan Qaboos University Med J, 7: 157-160.

11. Dunkelgrun $M$, lesaka $K$, Park SS, Kummer FJ, Zuckkerman JD (2003) Interobserver reliability and intraobserver reproducibilityin suprascapular notch typing. Bull Hosp Joint Dis, 61: 118-122.

12. Edelson JG (1995) Bony bridges and other variations of the suprascapular notch. J Bone Joint Surg Br, 77: 505-506.

13. Gosk J, Urban M, Rutowski R (2007) Entrapment of the suprascapular nevre: anatomy, etiology, diagnosis, treatment. Ortop Traumatol Rehabil, 9: 68-74.

14. Ghodadra N, Nho S, Verma N, Reiff S, Piasecki D, Provencher M, Romeo A (2009) Arthroscopic decompression of the suprascapular nerve at the spinoglenoid notch and suprascapular notch through the subacromial space. Arthroscopy, 25: 439-445.

15. Habermeyer P, Brunner U, Wiedemann E, Wilhelm K (1987) Compression syndromes of the shoulder and their differential diagnosis. Orthopade, 16: 448-457.

16. Holzgraefe M, Kukowski B, Eggert S (1994) Prevalence of latentand manifest suprascapular neuropathy in high-performancevolleyball players. Br J Sport Med, 28: 177-179.

17. Hrdlicka A (1942) The adult scapula: visual observations. Am J Phys Anthropol, 29: 73-94.

18. Hrdlicka A (1942) The adult scapula: addition al observations and measurements. Am J Phys Anthropol, 29: 363-415.

19. Johnson D (2008) Pectoral girdle, shoulder region and axilla. In: Standring S ed. Gray's anatomy. $40^{\text {th }}$ Ed, Elsevier, Churchill-Livingstone, p. 796.

20. Karatas GK, Gogus F (2003) Suprascapular nerve entrapment in newsreel cameramen. Am J Phys Med Rehabil, 82: 192-196.

21. Khan AM, Guillet MA, Fanton G (2001) Volleyball: rehabilitation and training tips. Sports Med Arthroscopy Rev, 9: 137-146.

22. Khan MA (2006) Complete ossification of the superior transverse scapular ligament in an Indian male adult. Int J Morphol, 24: 195-196.

23. Kim SH, Kim SJ, Sung CH, Koh YG, Kim YC, Park YS (2009) Arthroscopic suprascapular nerve decompression at the suprascapular notch. Knee Surg Sports Traumatol Arthrosc, 17: 1504-1507.

24. Kopell HP, Thompson WAL (1959) Pain and the frozen shoulder. Surg Gynecol Obstet, 109: 92-96.

25. Lafosse L, Tomasi A, Corbett S, Baier G, Willems K, Gobezie R (2007) Arthroscopic release of suprascapular nerve entrapment at the suprascapular notch: technique and preliminary results. Arthroscopy, 23: 34-42

26. Ling SC, Chen CF, Wan RX (1990) A study on the vascular supply of the supraspinatus tendon. Surg Radiol Anat, 12: 161-165.

27. Mestdagh M, Drizenko A, Ghestem P (1981) Anatomical basis of suprascapular nerve syndrome. Anat Clin, 3: 67-71.

28. Moore KL, Dalley AF, Agur AM (2010) Clinical oriented anatomy. 6th Ed. Lippincott Williams and Wilkins, Philadelphia, pp. 1-1168.

29. Moriggl B (1997) Moglichkeiten und Grenzen des Sonographie osteofibroser Kanale im Schulterbereich. Grundlagen Ann Anat, 179: 355-373.

30. Moriggl B, Jax P, Milz S, Buttner A, Benjamin M (2001) Fibrocartilage at the entheses of the suprascapular (superior transverse scapular) ligament of man: a ligament spanning two regions of a single bone. J Anat, 199: 539-545. 
31. Naidoo N, Lazarus L, De Gama BZ, Satyapal KS (2014) The variant course of the suprascapular artery. Folia Morphol, 73: 206-209.

32. Natsis K, Totlis T, Tsikaras P, Appell HJ, Skandalakis $P$, Koebke J (2007) Proposal for classification of the suprascapular notch: astudy on 423 dried scapulas. Clin Anat, 20: 135-139.

33. Olivier G (1960) Pratique anthropologique. Le scapulum. Vigot Freres, Paris, pp. 194-203.

34. Osuagwu F, Imosemi I, Shokunbi M (2000) Complete ossification of the superior traverse scapular ligament in a Nigerian male adult. Int J Morphol, 23: 121-122.

35. Osuagwu F, Imosemi I, Oladejo O (2004) Sources of cadaver used for dissection at the Ibadan Medical School, Nigeria: analysis of a three year data. Afr J Biomed Res, 7: 93-95.

36. Pećina M, Krmpotić-Nemanić J, Markiewitz A (1997) Tunnel syndromes: peripheral nerve compression syndromes. $2^{\text {nd }}$ Ed. CRC Press, Boca Raton, pp. 1-313.

37. Polguj M, Jedrzejewski K, Podgorski M, Topol M (2011) Morphometric study of the suprascapular notch: proposal of classification. Surg Radiol Anat, 33: 781-787.

38. Polguj M, Podgórski M, Jędrzejewski K, Topol M (2012) The double suprascapular foramen: unique anatomical variation and the new hypothesis of its formation. Skeletal Radiol, 41: 1631-1636.

39. Polguj M, Rozniecki J, Sibinski M, Grzegorzewski A, Majos A, Topol M (2015) The variable morphology of suprascapular nerve and vessels at suprascapular notch: a proposal for classification and its potential clinical implications. Knee Surg Sports Traumatol Arthrosc, 23: 1542-1548.

40. Post M (1999) Diagnosis and treatment of suprascapular nevre entrapment. Clin Orthop Relat Res, 368: 92-100.

41. Prescher A (2000) Anatomical basics, variations, and degenerativechanges of the shoulder joint and shoulder girdle. Eur J Radiol, 35: 88-102.

42. Rengachary SS, Burr D, Lucas S, Hassanein KM, Mohn MP, Matzke H (1979) Suprascapular entrapment neuropathy: a clinical, anatomical, and comparative study. Part 1: clinical study. Neurosurgery, 5: 441-446.

43. Rengachary SS, Burr D, Lucas S, Hassanein KM, Mohn MP, Matzke H (1979) Suprascapular entrapment neuropathy: a clinical, anatomical, and comparative study. Part 2: anatomical study. Neurosurgery, 5: 447-451.
44. Ringel SP, Treihaft M, Carry M, Fisher R, Jacobs P (1990) Suprascapular neuropathy in pitchers. Am J Sports Med, 18: 80-86.

45. Shaibani A, Workman R, Rothschild BM (1993) The significance of enthesopathy as a skeletal phenomenon. Clin Exp Rheumatol, 11: 399-403.

46. Silva J, Aureliano-Rafael F, Sgrott E, Silva S, Babinski M, Fernandes R (2007) High incidence of complete ossification of the superior transverse scapular ligament in Brazilians and its clinical implications. Int J Morphol, 25: 855-859 .

47. Ticker JB, Djurasovic M, Strauch RJ, April EW, Pollock RG, Flatow EL, Bigliani LU (1998) The incidence of ganglion cysts and other variations in anatomy along the course of the suprascapular nerve. J Should Elb Surg, 7: 472-478.

48. Toneva D, Nikolova S (2014) Morphology of suprascapular notch in medieval skeletons from Bulgaria. Folia Morphol, 73: 210-215.

49. Tubbs RS, Smyth MD, Salter G, Oakes WJ (2003) Anomalous traversement of the suprascapular artery through the suprascapular notch: a possible mechanism for undiagnosed shoulder pain? Med Sci Monit, 9: 116-119.

50. TubbsRS, Nechtman C, D'AntoniAV, Shoja MM, Mortazavi MM, Loukas M, Rozzelle CJ, Spinner RJ (2013) Ossification of the suprascapular ligament: A risk factor for suprascapular nerve compression? Int J Shoulder Surg, 7: 19-22.

51. Urguden M, Ozdemir H, Donmez B, Bilbasar H, Oguz N (2004) Is there any effect of suprascapular notch type in iatrogenic suprascapular nerve lesions? An anatomical study. Knee Surg Sports Traumatol Arthrosc, 12: 241-245.

52. Vallois HV (1925) L'os acromial dans les races humaines. L'Anthropologie, Paris, 35: 977-1022.

53. Vallois HV (1926) Variations de la cavite glenoide de L'omoplate. Soc Biol Comptes Rendus Hebdomadaires Seances Etmemoires, 94: 559-560.

54. Wang HJ, Chen C, Wu LP, Pan CQ, Zhang WJ, Li YK (2011) Variable morphology of the suprascapular notch: an investigation and quantitative measurements in Chinese population. Clin Anat, 24: 47-55.

55. Yücesoy C, Akkaya T, Özel O, Cömert A, Tüccar E, Bedirli N, Ünlü E, Hekimoflu B, Gümüş H (2009) Ultrasonographic evaluation and morphometric measurements of the suprascapular notch. Surg Rad Anat, 31: 409-414. 